\title{
Therapeutic Monoclonal Antibodies for Migraine
}

\author{
Stephen Silberstein, MD \\ Professor of Neurology and Director, Jefferson Headache Center, Thomas Jefferson University, Philadelphia, US
}

\begin{abstract}
Monoclonal antibody (mAb) treatment has revolutionized the approach to many diseases. They comprise immunoglobulin $\mathrm{G}$ (IgG) isotypes. Calcitonin gene-related peptide (CGRP) is important in migraine pathogenesis. Four mAbs that target either CGRP or the CGRP receptor are in development for prophylaxis of episodic migraine or chronic migraine. Preliminary data suggest that they are effective.
\end{abstract}

\section{Keywords}

Monoclonal antibodies, migraine treatment, calcitonin gene-related peptide (CGRP)

Disclosures: Stephen Silberstein, MD, serves as a consultant and/or advisory panel member and receives honoraria from Alder Biopharmaceuticals, Allergan, Inc., Amgen, Avanir Pharmaceuticals, Inc., Dr. Reddy's Laboratories, eNeura Inc., ElectroCore Medical, LLC, Medscape, LLC, Medtronic, Inc., Mitsubishi Tanabe Pharma America, Inc., NINDS, Supernus Pharmaceuticals, Inc., Trigemina, and Teva Pharmaceuticals. No funding was received for the publication of this article.

Open Access: This article is published under the Creative Commons Attribution Noncommercial License, which permits any noncommercial use, distribution, adaptation, and reproduction provided the original author(s) and source are given appropriate credit.

Received: February 2, 2015 Accepted: February 13, 2015 Citation: US Neurology, 2015;11(1):64-5 DOl: 10.17925/USN.2015.11.01.64

Correspondence: Stephen Silberstein, MD, Thomas Jefferson University, Jefferson Headache Center, 900 Walnut Street, Suite 200, Philadelphia, PA 19107, US, E: stephen.

silberstein@jefferson.edu

Monoclonal antibody (mAb) treatment has revolutionized the approach to many diseases and represents a fast-growing area of drug development. ${ }^{1,2}$ They are composed of immunoglobulin G (IgG) isotypes, divided into four subclasses. ${ }^{3}$ In 1986, the US Food and Drug Administration (FDA) approved muromonab-CD3, the first mouse-derived therapeutic mAb indicated for transplant rejection. ${ }^{4}$ Human or "fully human" mAbs were later developed in 2002 that contained human heavy and light chains. How are mAb named? The stem - mA $b$ indicates an mAb, and the substem indicates the species: murine (-omAb), chimeric (-ximAb), humanized $(-z u m A b)$, and human (-umAb). ${ }^{5}$ Antibodies can bind directly to the ligand or its receptor. ${ }^{6}$ Binding to a cell-surface receptor prevents binding of the ligand and causes downstream processes (e.g. receptor dimerization, receptor breakdown, and signal transduction). ${ }^{6}$

Monoclonal antibodies are delivered parenterally because of their large size and hydrophilicity. They are not filtered by the kidney or excreted into the urine intact. Their average serum half-life is weeks to months, allowing them to be administered monthly. ${ }^{7,8}$

\section{Monoclonal Antibodies in Migraine Prophylaxis}

Calcitonin gene-related peptide (CGRP) is important in migraine pathogenesis. ${ }^{9}$ Recently, multiple human monoclonal antibodies that specifically target the human CGRP receptor have been generated. The inhibition of capsaicin-induced increases in dermal blood flow has been used as an in vivo pharmacodynamic model in humans and nonhuman primates during their development. Topically applied capsaicin stimulates dermal neurons to release CGRP resulting in a localized increase in dermal blood flow. The CGRP receptor mAb prevented capsaicin-induced increase in dermal blood flow in cynomolgus monkeys for up to 7 days. ${ }^{10}$

The immunochemical distribution of CGRP receptor mAb has been tested. This recognizes the functional CLR/RAMP1 receptor complex, but not its individual components. CGRP receptor complexes are expressed on multiple levels in the trigeminal vascular system of the cynomolgus monkey: 1) in the meningeal vasculature innervated by CGRP-positive nerve fibers; 2) in neurons and satellite cells in the trigeminal ganglion; and 3) in neurons in the spinal trigeminal nucleus. The CGRP receptor localization is consistent with CGRP's role in trigeminal sensitization and suggests that interfering with CGRP receptor transmission may be beneficial for the treatment of migraines. ${ }^{11}$

Another approach is CGRP antibodies that would inhibit neurogenic vasodilation with a long duration of action. Incorporating two rat blood-flow models measuring electrically stimulated vasodilation in the skin or the middle meningeal artery, vasodilatatory responses were found largely dependent on the neurogenic release of CGRP from sensory afferents. Treatment with anti-CGRP antibodies inhibited skin vasodilation or the increase in middle meningeal artery diameter to a similar magnitude as treatment with CGRP receptor antagonists, but with a slower onset of action. The inhibition was evident 1 week after dosing. Chronic treatment with antiCGRP antibodies had no detectable effects on heart rate or blood pressure. ${ }^{12}$

Four mAbs that target either CGRP or the CGRP receptor are currently in development for prophylaxis of episodic migraine (four to 14 headache 
days per month) or chronic migraine ( $\geq 15$ headache days per month). LY2951742 is a humanized mAb targeted against the CGRP ligand (CGRP itself). In a phase II study of patients with episodic migraines, subcutaneous (SC) administration of LY2951742 (150 mg every 2 weeks) resulted in a reduction from baseline at week 12 of 1.2 days compared with placebo. ${ }^{13}$ In a separate phase II study, ALD403, another humanized mAb against the CGRP ligand, showed similar results at weeks 5 to 8; intravenous (IV) administration of ALD403 (1,000 mg) reduced monthly migraine headaches by 1.0 day compared with the placebo group. ${ }^{14}$ Monthly dosing (SC) of LBR101, a third humanized mAb against the CGRP ligand, and monthly dosing
(SC) of AMG 334 are also being evaluated in phase II clinical trials. AMG 334 is unique among the novel CGRP mAbs for migraine prevention in that it is a fully human mAb that targets the CGRP receptor rather than CGRP itself. Results of the AMG 334 will be presented at the Biennial Congress of the International Headache Society, Valencia, Spain, May 14-17, 2015. Monoclonal antibodies offer advantages: high target specificity, no liver or kidney metabolism, and a long half-life. The safety and efficacy of monoclonal antibodies against the CGRP ligand or CGRP receptor are currently being investigated and will help determine the importance of these potentially new treatments for migraine prevention.
1. Buss NA, Henderson SJ, McFarlane M, et al., Monoclonal antibody therapeutics: history and future, Curr Opin Pharmacol, 2012;12:615-22.

2. Reichert JM, Therapeutic monoclonal antibodies approved or in review in the European Union or United States. Available at: http://www.antibodysociety.org/news/approved_mabs.php (accessed November 15, 2014)

3. Jefferis $\mathrm{R}$, Isotype and glycoform selection for antibody therapeutics, Arch Biochem Biophys, 2012;526:159-66.

4. Nelson AL, Dhimolea E, Reichert JM, Development trends for human monoclonal antibody therapeutics, Nat Rev Drug Discov, 2010:9:767-74.

5. International Nonproprietary Names (INN) for biological and biotechnological substances, World Health Organization, 2013

6. Carden CPA, Arkenau HT, de Bono JS, Optimising the development of antibodies as treatment for cancer. In: Hidalgo ME, Garrett-Mayer E, Clendeninn NJ, eds, Cancer Drug Discovery and Development, New York, NY: Springer
Science+Business Media, 2011

7. Mould DR, Sweeney KRD, The pharmacokinetics and pharmacodynamics of monoclonal antibodies-mechanistic modeling applied to drug development, Curr Opin Drug Discov Devel, 2007:10:84-96.

8. Wang W, Wang EQ, Balthasar JP, Monoclonal antibody pharmacokinetics and pharmacodynamics, Clin Pharmacol Ther, 2008;84:548-58.

9. Bell IM, Calcitonin gene-related peptide receptor antagonists: New therapeutic agents for migraine, J Med Chem, 2014; $57: 7838-58$

10. Zhu D, Zhang J, Zhou $L$, et al., A human CGRP receptor antagonist antibody, AA95, is effective in inhibiting capsaicininduced increase in dermal blood flow in cynomolgus monkeys, 54th Annual Scientific Meeting, American Headache Society, Los Angeles, CA, 2012;022.

11. Liu H, Xu C, Shi L, et al., Immunohistochemical localization of the CLR/RAMP1 receptor complex in the trigeminovascular system of the cynomolgus monkey, 53rd Annual
Scientific Meeting American Headache Society, Washington DC, 2011; P2

12. Zeller J, Poulsen KT Sutton JE, et al CGRP function-blocking antibodies inhibit neurogenic vasodilatation without affecting heart rate or arterial blood pressure in the rat, Br $\perp$ Pharmacol, 2008:155:1093-103.

13. Dodick DW, Goadsby PJ, Spierings ELH, et al., Safety and efficacy of LY2951742, a monoclonal antibody to calcitonin gene-related peptide, for the prevention of migraine: a phase 2, randomised, double-blind, placebo-controlled study, Lancet Neurol, 2014:13:885-92.

14. Dodick DW, Goadsby PJ, Silberstein SD, et al., Safety and efficacy of ALD403, an antibody to calcitonin gene-related peptide, for the prevention of frequent episodic migraine: a randomised, double-blind, placebo-controlled, exploratory phase 2 trial, Lancet Neurol, 2014;13:1100-7.

15. Foltz IN, Karow M, Wasserman SM, Evolution and emergence of therapeutic monoclonal antibodies: what cardiologists need to know, Circulation, 2013:127:2222-30. 